\title{
THE POSITION AND RESIDENTIAL PATTERNS OF ETHNIC GROUPS IN PARAMARIBO'S DEVELOPMENT IN THE TWENTIETH CENTURY
}

Suriname is a prime example of a multicultural Caribbean society. Suriname's capital, Paramaribo, has more different ethnic and cultural groups than any other Caribbean city. Whereas in a town like Kingston there is primarily a distinction between black and white, and in Georgetown and Port of Spain between black and Indian, Paramaribo's population is made up of three main ethnic groups: Creoles, Hindustanis, and Javanese; and at least seven smaller ones: Amerindians, Europeans, Maroons, Chinese, Lebanese, and Brazilians. Moreover, over time an ethnically mixed group formed that originally consisted of people of mixed European and African heritage (known then as mulattoes), though it now also includes descendants of other mixed ethnic relations. In this group of mixed ethnicities, not one is numerically predominant, and they come from all over the world: Western Europe, Western Africa, Bihar and West Bengal, Java, different parts of China, Lebanon, and more recently Brazil. One could say globalization took place in Suriname during its very founding as a plantation society (see also Hoefte \& Meel 2001).

The present-day population of Paramaribo largely descends from forced and semi-forced immigrants who came to the country mainly during the plantation era, though in sequence. Their move into the capital was also sequential. After the abolition of slavery in 1863 and the immigration of Asian laborers to the plantations, Paramaribo became a "Creole" city dominating the "Asian" rural areas. As, at the beginning of the twentieth century, more Hindustanis and Javanese entered the city in search of new economic opportunities and a better education for their children, the ethnic composition of the capital gradually changed. The city became even more ethnically diverse, and its population differentiated when ethnic groups from the interior of the country, the Amerindians and the Maroons, came to live in it. Paramaribo still receives new migrants today, from Brazil and from China.

With so many ethnic groups living together in a confined geographic setting and united in the still weakly developed specifically Surinamese national

New West Indian Guide / Nieuwe West-Indische Gids vol. 79 no. 3 \& 4 (2005):239-271 
culture, one can expect that ethnic identity and ethnic boundaries are important in shaping urban society. People are explicit about their ethnic identity and culture, and they are given shape in a way that asserts one's place in society. Ethnicity in Suriname has clear cultural, political, and economic dimensions, and it is often through ethnic networks that people have access to resources. Moreover, ethnicity can be assumed to have a distinct spatial dimension, too, given the strong orientation people have toward their own ethnic group.

An analysis of the historical development of Paramaribo reveals that soon after their arrival in the city, ethnic groups, either by force or voluntarily, took up and maintained distinct socioeconomic and spatial positions, resulting in ethnic labor specialization, economic stratification, and spatial concentration and segregation, though not in a strict sense. Have socioeconomic and spatial differentiation continued over time, or have ethnic groups tended toward increasing integration? To answer this question we analyzed different historical eras, namely the period of slavery, the arrival of former East Indian and Javanese plantation laborers in the city, and, in particular, the recent past.

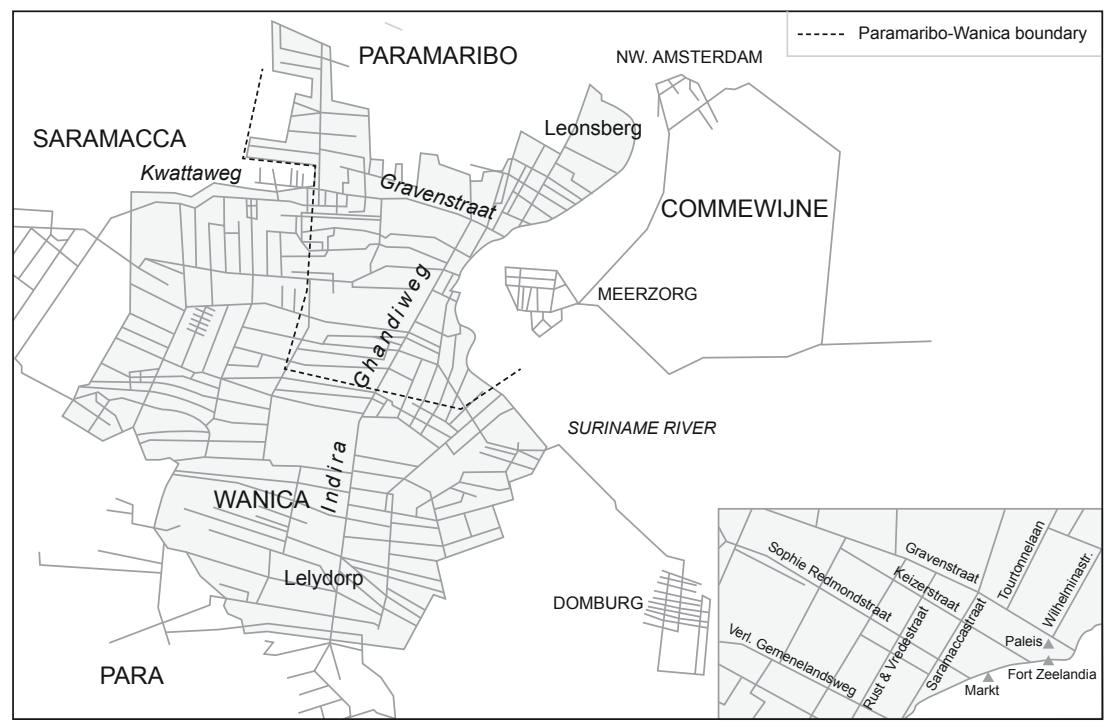

Map 1. Greater Paramaribo

It would be logical to assume that initially, in the decades after slavery and indentured labor, with new migrant groups entering the receiving society and a strong sense of ethnic identity and ethnic boundaries, the city's ethnic groups would be quite segregated. Likewise, one would expect ethnic segregation to have diminished in the modern period, for the largest ethnic groups have been living together in the city for many decades and they have had 
many decades in which they had the chance to take part in socialization and acculturation processes; they have increased access to political, educational, and economic resources; interethnic contact occurs on a daily basis, at least in the workplace; and ties to the country of origin have lessened. One would even expect to see that ethnic residential segregation would in part or even entirely have changed into a spatial differentiation on the basis of income, that is, purchasing power on the land and housing market.

In this article we have therefore primarily attempted a historical analysis of ethnic residential patterns in Paramaribo, and their correlation to the changing socioeconomic positions of the various ethnic groups. This is not an analysis of the political positions of the different ethnic groups; the political dimension of ethnicity is mainly touched upon as a factor determining spatial concentration and segregation where, for instance, the government distributed public housing. Historical and current material available in publications, censuses ${ }^{1}$ and household surveys ${ }^{2}$ forms the empirical basis for our attempt to sketch a quantitative portrait of the socioeconomic and residential positions of ethnic groups in Paramaribo.

\section{EThNiC Identity And EThniC Boundaries}

An individual's membership of an ethnic, religious, or geographic community greatly influences one's identity and actions. Individuals, communities, and groups express and reinforce their identity and culture through language, religion, endogamy and cultural traditions, among others. Marrying within one's ethnic group, for example, is an important way of maintaining ethnic boundaries and identities. Ethnic groups may inhabit shared territories, in which case boundaries, both ethnic and territorial, define them, more so than ethnic culture does (Sanders 2002:328).

As ethnic groups join new societies, ethnic identity and ethnic boundaries are key variables in determining their position in those new societies, more so for the first generation than the second, which has taken part in the acculturation, and perhaps eventually assimilation, processes. How an ethnic group is received in a new society varies between receiving societies as well as between ethnic groups. During the first stage of participation in the new society, the incoming ethnic group has to compete with it for resources, which can cause ethnic conflicts. One of the incoming ethnic group's most

1. Only few relevant data from the most recent census (2004) in Paramaribo were available at the time of writing. The most recent usable census dates from 1980 .

2. The method used to collect and analyze data is described in more detail in the appendix. 
important means for economic survival in the first period in the new society is a social network. A network of people of the same ethnicity can give access to scarce resources, such as jobs, informal training, and loans, in short, economic opportunities that migrants need so dearly because of their disadvantaged position owing to their command of the new language, their lack of formal training within the educational system of their new country, their incomplete understanding of the new value system, and the possible discrimination by the dominant group or groups. In societies where ethnic networks are an important means of gaining access to scarce resources, ethnic identity is normally stronger, as are ethnic boundaries.

Through ethnic networks, minority groups can come to monopolize particular economic opportunities within limited sections of the labor market. An ethnic group will demand specific goods and services that are best understood by members of the group itself, giving rise to "ethnic" entrepreneurship and a labor market segmented along ethnic lines. Segmentation of this sort can be seen as a kind of ethnic boundary; resources generated within the group can be protected by closed ethnic boundaries. These "enclave economies" not only generate an income and a measure of affluence for its participants, but they also lead to stratification within the group.

The livelihood strategies of migrant ethnic groups may be differential, that is, they combine activities to make a living and limit their vulnerability. The ethnic groups need access to assets and to mobilize them. In an urban context, labor and housing are two of the most important assets for households, especially poor ones. When a household income declines, the urban poor most commonly mobilize additional labor, usually women, but also children (Moser 1998). In addition, the home can be used to diversify the income through home-based financial activities (Verrest, forthcoming), as well as through letting rooms, where the home is owned by its inhabitants. Human capital, especially in the form of education, but also of household relations, is another asset. Household relations mean that members of one household can pool their income and share their consumption, but whether the relations within a household are an asset is dependant upon its life cycle, size, and structure. Poor households are more likely to be headed by a female, and they more often have extended families. Remittances from household and family members abroad can be another, and sometimes important, source of income.

\section{Residential Patterns and Segregation}

The distribution of a population over the urban space cannot be characterized by randomness, nor is it even. Where people reside and how they live are expressions of the social position they occupy, a position based on income, household characteristics, ethnic background, and migration history; in the 
past, people's legal position (whether or not one was a slave) was also an important factor for social stratification in plantation societies such as those in the Caribbean. Thus, there is a certain measure of spatial segregation between people, households, and groups with different social positions within urban societies. People of a certain background or class, or from a certain group, live together or create a distance between themselves and others on the basis of the quality and location of the house and their sociocultural relations and preferences.

We analyzed residential patterns in Paramaribo in terms of spatial segregation (the residential separation of groups within a broader population) and concentration (the much higher occurrence of members of a group in a certain area, as compared to their proportion in the city as a whole). ${ }^{3}$

The concentration of an ethnic group within a specific territory, such as a neighborhood, helps to maintain ethnic boundaries and ethnic identity. Policy-makers often see the concentration of ethnic groups in a specific area as problematic, for they see it as reflecting an absence of choice and preventing the particular ethnic group taking part in wider society. Moreover, ethnic concentration leads to a spatial concentration of problems (Musterd, Ostendorf \& Breebart 1998).

The economic position of households is another sorting mechanism, and one of the most important ones, underlying urban residential patterns. Those households with the most money have the greatest choice in locations. Residential segregation is therefore related to competition for scarce space.

The demographic characteristics, and more specifically the phase in the family life cycle, of a household influence what location in a city it prefers. A household has different needs for space depending on its age structure, size, and composition. Both in Western cities and cities in developing countries there is a tendency for one- and two-person households to be concentrated in the city center, close to work and urban facilities, whereas households with children require more space and prefer to live outside the city center, or even outside the city.

Finally, the state, on the national or local level, can influence residential patterns. The government is largely able to regulate the housing market and access to it, and does so either directly by providing land or housing to specific groups, or indirectly with general economic policies, laws, and services.

3. We computed these measures statistically using the index of dissimilarity that is given in the appendix. 


\section{The Historical Roots of Socioeconomic and Residential POSITIONS IN PARAMARIBO}

At its founding in the seventeenth century, Paramaribo was the colony's political and economic center. In the first half of the nineteenth century, Paramaribo was a small city of around 16,000 people in which free people and slaves lived together. In 1830 the majority of the urban population was still enslaved. However, in 1850, 57 percent of the population lived and moved freely; this percentage increased significantly in the years before 1863, the year in which slavery was abolished (Hoogbergen \& Ten Hove 2001). In those years the population was divided into slaves and non-slaves on the one hand, and whites (mainly Dutch and Jews), mulattoes, and blacks on the other. Where did these groups live? Did they live in segregated wards, isolated from each other, or were they blended with other groups?

The key political and economic locations, from which the rulers, plantation owners, and traders dominated the colony, were in the center of Paramaribo. The governor's mansion and offices were in the heart of the city. Export and import trade, around which the colony was structured, were conducted from the center of the city near the harbor. As in all pre-industrial towns, the elite of the city, plantation owners and managers, as well as the merchants, lived in townhouses in the city center.

The center of town did not, however, have only high-grade properties, nor was there a "cordon sanitaire" around it as was the norm for African colonial cities. Slaves were forced to live behind the houses of the wealthy, often in one-room sheds built in a row. Residential patterns in the center of the city were thus based on legal distinctions between owners and slaves, with the owner's main house and his slave's sheds being in the same yard. The residential pattern also had an economic basis, for the yard slaves had to work for their masters as house slaves, as handicraft workers, or as hawkers; even plantation slaves who were brought to the city temporarily were housed in these yards. Furthermore, the residential patterns in the city were ethnically determined, with the white inhabitants of the main house living separately from the colored inhabitants of the yard houses. We have not found evidence that there were any legal or social barriers preventing white and mixed people living alongside, or even together with, each other. In fact, there were colored people in many so-called white households.

Free people who worked at lower-level jobs and often did not have slaves also populated the city center. They lived in low-grade houses in the smaller streets. The further outside the city a house was, the poorer its quality. In nineteenth-century documents buildings near the city center were described as houses, and not shacks, whereas the edge of the city, said a report from those years, was made up of the miserable huts of the poor. 
After the abolition of slavery in 1863 , most ex-slaves left the plantations and some became smallholders in the rural areas while others went directly to the city. Once plant diseases diminished the quality and quantity of their produce, most smallholders eventually abandoned agriculture to try their luck in the city. The migration of Creoles from rural to urban areas was slow but steady at the end of the nineteenth century, its tempo being determined by the relative difference in the economic circumstances in the country and city. However, at the beginning of the twentieth century it picked up speed.

In the city Creoles took up lower-level government positions, particularly in the police service, and they became active in small-scale industry and services where no formal education was required: carpentry, shoemaking, smithcraft, and porterage. These were trades almost exclusively practiced by Creoles. The Dutch and Jews, as well as the group of mulattoes who had been born and raised in the city, held most higher and mid-level government jobs, and positions in education.

The economic position of the Creoles determined their residential location more than their ethnic background did. Although mulattoes and other lighterskinned Creoles tended to live in the city center, and darker Creoles on the outskirts of the city, it was in fact as a result of differences in socioeconomic status between the two groups. More than other ethnic groups, residential areas occupied by Creoles were heterogeneous, with relatively low levels of concentration and segregation. Nonetheless, the residential patterns reflected differences in affluence, and the residential patterns of Creoles showed more heterogeneity than homogeneity. We can therefore only explain nineteenthand early twentieth-century Paramaribo residential patterns indirectly, for ethnic background was not an independent variable.

In the first decades of the twentieth century, the political and economic situation of Paramaribo did not change significantly. In 1921 the city had 44,000 inhabitants, which was 40 percent of the national population. Slavery had, however, been abolished, and the population's ethnic composition was changing. Europeans still held the political and economic power, though they formed a minority (2.2 percent). In 1921,81 percent of the city's population was Creole (black or mulatto), and Hindustanis (7.7 percent), Chinese (2.2 percent), and Javanese (1.2 percent) now also formed part of the townscape.

Distinctions between the various groups' opportunities and preferences for employment and residential locations were such that the labor market became segmented. The labor market mirrored colonially stratified Surinamese society. Income data from 1930 indicate that the Dutch, Jews, and mulattoes still formed the elite. Large segments of the Creole population, and particularly the new Asian immigrants, possessed and earned significantly less.

Hindustanis began migrating to Paramaribo around the beginning of the twentieth century, about fifty years after the urban migration of Creoles. By 1921, Hindustanis were the second-largest ethnic group in the city. After 
finishing their period of indentured labor on plantations, most Hindustanis left the estates and started off as smallholders in the coastal area and around Paramaribo, where they successfully developed rice production.

The Hindustanis who first came to Paramaribo were a select group, that is, many of them were born in Calcutta, i.e. an urban area, and they probably tried to take up their old trades and occupations in hopes of progressing financially after they finished their term of indentured labor. Whatever might have been their reasons, they took up work that did not require a specific formal Surinamese education, such as in the trade and transport sector, where they were self-employed. Some Hindustani children living in the countryside were sent to the capital for higher education by their parents, sometimes stimulated by the Catholic and Protestant missions that ran children's homes for Hindustani children in Paramaribo. The first Hindustani intellectuals emerged from this group, and some of these later turned to politics, where they contributed to the emancipation process of their ethnic group.

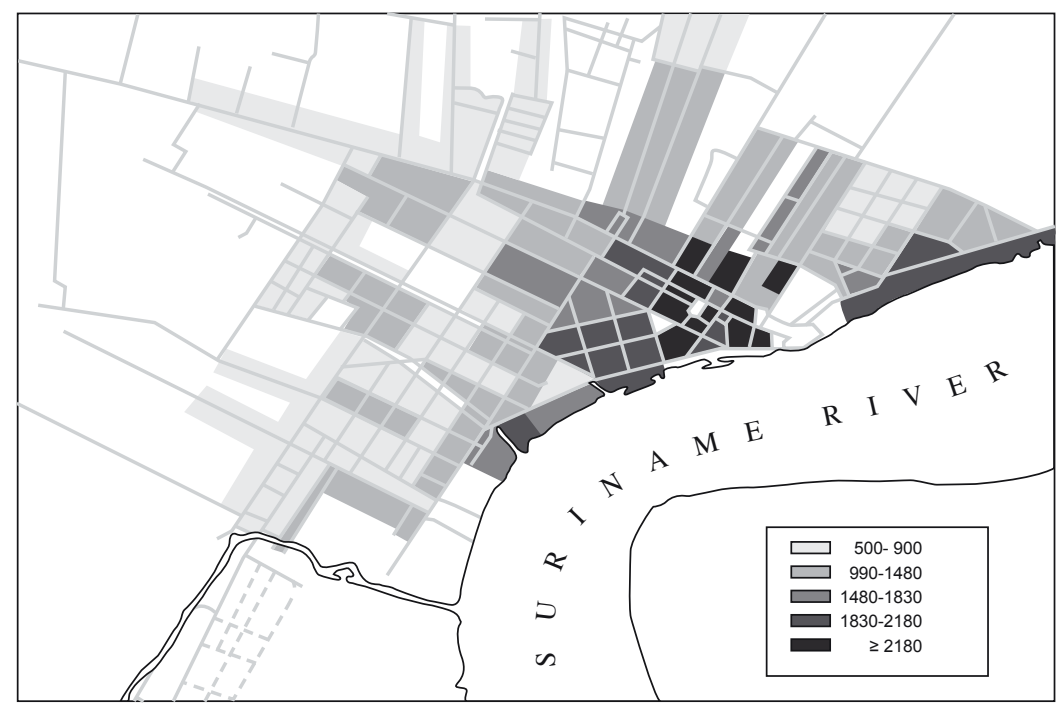

Map 2. Average income of taxpayers in Paramaribo, 1930 (in Surinamese guilders of that year). Source: Income tax register of 1930 (De Bruijne 1976)

The Javanese were the last of the three major ethnic groups to arrive in Suriname: their migration to the colony continued until the 1930s. They were also the last of these groups to migrate to the city, their urban migration only becoming significant around the 1960s. Even in 1992, half the Javanese heads of household in Paramaribo were born in the rural areas of Suriname and the Dutch East Indies. Upon their arrival in the city, the Javanese, charac- 
terized by a very low level of formal education - much lower even than the Hindustanis at that time - did mainly low-level work such as peddling, or they became servants or drivers, and most particularly, gardeners: as late as 1964,50 percent of the gardeners in the city were Javanese. The Javanese were noticeably absent among higher- and mid-level jobs.

During the first half of the twentieth century, the Hindustanis and Javanese, each with their own language and religion, lived in the city, largely isolated in a social and cultural sense. According to the census of 1921, only a few of them joined the then dominant religion in the city, Christianity. ${ }^{4}$ Only 4 percent of Hindustani males, in 1921, had a non-Hindustani partner, though their children were drawn into the dominant Western-oriented culture through formal education, the official language for which was Dutch.

Until World War II, the elite still mainly occupied the center of the city (see Map 2). High-income households were located in the center of the city and, to some extent, along the river in a northerly direction. Poor people lived on the fringe of the city. Whereas in the center at least 22 percent of households paid income tax, in the outer circle it was only 7 percent, and the average income was only one-quarter that of the city center. In the city center, in yards directly behind town houses, offices and warehouses, there were still yard houses inhabited by poor people, often migrants from the rural districts who were mainly Creole. Renting out small yard houses had become a commercial undertaking.

Most Hindustanis lived in the periphery of the city, and their smallholdings were gradually incorporated into the city, though they continued to engage in agricultural activities. Some Hindustani migrants settled in the city center, around the main trading streets and shops. Other concentrations of Hindustanis could be found in the north, where they were able to buy large but cheap lots suitable for combining living and financial activities, such as stalling carts and keeping animals used for transport. Hindustanis were also living in the south, along the main road leading to the rural areas. Places where Hindustanis were already living were attractive for other Hindustanis settling in the city because that is where they would most easily find their ethnic networks, which were essential to financial survival in a situation of strong ethnic labor segmentation. ${ }^{5}$ The historic location of Hindustanis can therefore be attributed mainly to their economic activities, as well as ethnic preferences and economic position. Taking into account their strongly differing cultural backgrounds and religious traditions, it is not surprising that Hindustanis showed much stronger patterns of residential concentration and segregation than did the Creoles.

4. There were also Christians among the Hindustani immigrants.

5. The great difference between the theoretical chance of a Hindustani having a Hindustani neighbor in Paramaribo, and the actual data (De Bruijne 1976:221) indicates the desire for ethnic proximity among Hindustanis. 


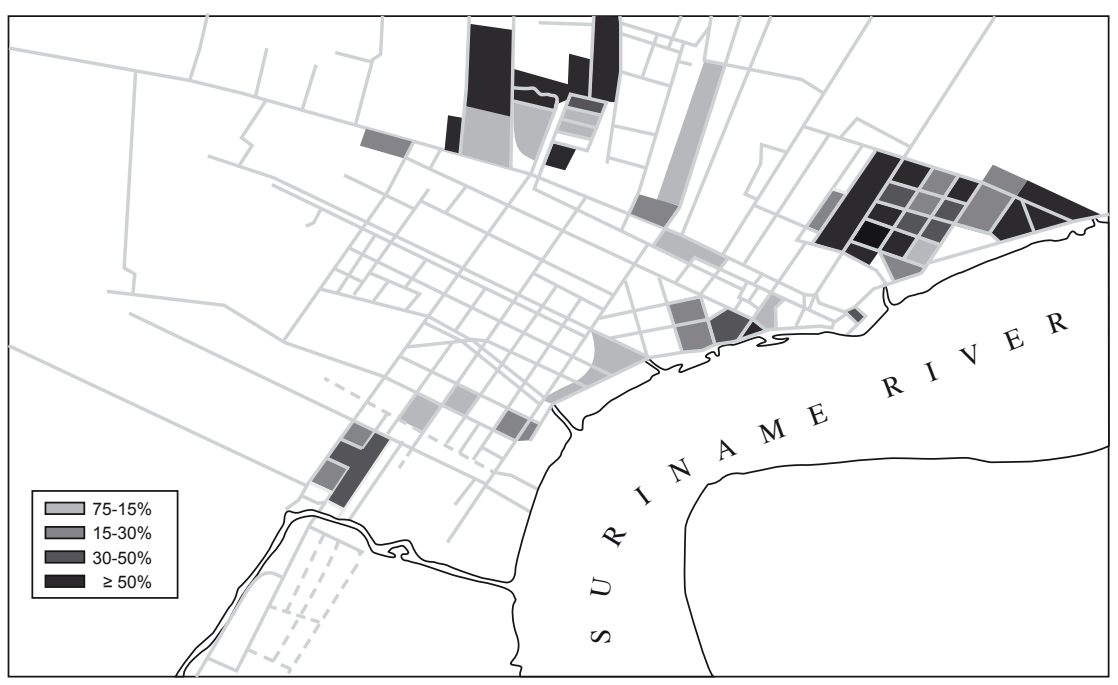

Map 3. The share of property owned by Hindustanis in Paramaribo in 1925

Table 1. Index of dissimilarity, centrality, and concentration in Paramaribo in 1918

\begin{tabular}{lcrrrrrr}
\hline Ethnic group & \multicolumn{4}{c}{ Dissimilarity } & Relative centrality & Concentration \\
& 1 & 2 & 3 & 4 & 5 & & \\
\hline 1. Creoles & $\mathrm{x}$ & 42 & 57 & 41 & 35 & 101 & 101 \\
2. Europeans & & $\mathrm{x}$ & 54 & 56 & 51 & 68 & 131 \\
3. Javanese & & $\mathrm{x}$ & 31 & 60 & 104 & 136 \\
4. Hindustanis & & & $\mathrm{x}$ & 56 & 113 & 125 \\
5. Chinese & & & & $\mathrm{x}$ & 85 & 121 \\
\hline
\end{tabular}

See the appendix for an explanation of the terms used.

Source: De Bruijne 1976:215.

Of the three major ethnic groups, Javanese showed the highest residential concentration and a great deal of dissimilarity with other urban ethnic groups, especially the elite - Europeans as well as Chinese. Particularly the latter group, mostly shopkeepers, settled in the center of the city and occupied corner buildings everywhere. In contrast, very few Javanese lived in the city center; most were concentrated in specific semirural areas - Javanese villages around the city which gradually became part of the urban fabric.

The relative dissimilarity and spatial segregation of each ethnic group is summarized in Table 1, which shows Creoles being distributed fairly evenly across the city. Europeans and Chinese were more concentrated in the city center, while Hindustanis and Javanese lived mainly in the periphery. 
We can conclude that for the late nineteenth and twentieth centuries, residential patterns were not primarily based on ethnic distinctions, that is, an explicit preference for spatial segregation from other ethnic groups. We could not determine specific differentiations (such as the place of birth) within the different ethnic groups. The population was distributed within the city according to differences in the wealth (and occupation) of the different groups, and only to some extent by a preference for ethnic proximity.

\section{PARAMARIBO TODAY}

Since the time of the plantations, Paramaribo, being the only city of importance in Suriname, has dictated the development of its hinterland. Although extractive industries based in the countryside - rubber, bauxite, oil, timber, gold - came to Suriname in the twentieth century the importance of the capital did not diminish.

Paramaribo owes its dominance primarily to the financial relations between the city and rural areas. Almost all sizeable companies and agencies, including those from the extractive industry, have their offices in the capital and have a significant effect on employment. Many of their field employees also live in the city. Today Paramaribo is still the node for the import of goods from abroad and distribution to the hinterland, as well as for the export of its primary goods.

All major government agencies are located in the capital, and all important administrative decisions about planning, budgets, and implementation are made in the city. The large government apparatus exacerbates the capital's sphere of influence; almost half the urban labor force is employed by the government. In the absence of a sizeable industrial sector (because of Suriname's small internal market, its unfavorable competitive position, and lack of consistent industrial policies) trade and services are the foundation of the urban labor market. Since the 1960 s, the state's institutions have been a means of providing social security and preventing social unrest. Because investments, decision making, and employment are all concentrated in Paramaribo, rural residents are even more aware that the city offers more economic and social opportunities than the country, with resultant rural-urban migration.

Thus there is an ever greater share of the Surinamese population living in greater Paramaribo. Between 1980 and 2004 the population of Suriname as a whole increased by 35.4 percent, with the population of the urban districts of Paramaribo and Wanica, which more or less constitute greater Paramaribo, increasing by 43.3 percent and 40.7 percent, respectively. According to the preliminary census results, in August of 2004 Suriname had 487,246 inhabitants, of whom an estimated 340,000 , or two-thirds of the population, live in and around the capital. 
Table 2. Ethnic composition of the population of Greater Paramaribo in 1992 (in percentages) ${ }^{6}$

\begin{tabular}{lc}
\hline Ethnic groups & 1992 \\
\hline Creoles & 35.2 \\
Ethnically mixed & 9.5 \\
Hindustanis & 32.6 \\
Javanese & 14.0 \\
Maroons & 5.2 \\
Chinese & $1.1^{\mathrm{i}}$ \\
Amerindians & 0.9 \\
Europeans & 0.8 \\
Others & $0.7^{\mathrm{ii}}$ \\
\hline Total & 100 \\
\hline
\end{tabular}

i. The size of the Chinese group was most likely underestimated and has increased considerably since.

ii. The migration of Brazilians to Paramaribo dates from the 1990s.

Source: Schalkwijk \& De Bruijne 1999:34.

The proportions of the ethnic groups in the urban population of Paramaribo has changed considerably since 1921. After World War II Paramaribo had become a multiethnic city, though Creoles still formed a small majority. In 1964, 59 percent of the population of greater Paramaribo - 142,000 people - was classified as Creole, 26 percent as Hindustani, and 6.5 percent as Javanese. Whereas the group of Creoles was born mostly in the city, many of the Hindustanis and Javanese were born in rural areas. In the following years, many Hindustanis and Javanese urbanized, not because they migrated to the city, but because their communities on the outskirts of the city were incorporated into the urban landscape. In 1992, the Creole group made up 38.8 percent of the urban population, whereas 10.7 percent of the urban residents considered themselves to be ethnically mixed. ${ }^{7}$ Hindustanis and Javanese accounted for 28.6 percent and 13.0 percent, respectively. There were considerably more Maroons in the city as they fled the war in the interior in the 1980s. An ethnic group that has recently made its way to the city is that of the Brazilians, who are linked to the large group of gold seekers exploiting the interior of the Surinamese jungle. In recent years, the Chinese community has also grown very significantly because of migration from China. ${ }^{8}$

6. All tables in this article have been taken from a survey of 4,000 households (heads of households) unless indicated otherwise; see Schalkwijk \& De Bruijne 1999.

7. According to our own urban survey, in the absence of other data.

8. Recent Chinese migrants come from other parts of China than the earlier Hakkaspeaking Chinese. 


\section{Present-day Sociocultural and Economic Standing of the ETHNIC GROUPS}

Ethnicity plays a primary role in the private sphere: in the home, in daily intercourse, in the way in which or with whom one lives, in the design of the home and its decoration. It affects one's choice of partner, the language one uses, the religion one professes, the political party one prefers, and to some degree the occupation one chooses. In microlevel Paramaribo, ethnic segregation as a social behavior is not publicly propagated among the ethnic groups, but life outside school and the workplace is clearly strongly influenced by ethnicity. Ethnic preference is perhaps most visible in situations where people can choose in whose company they want to be: private celebrations, be it a traditional Hindustani wedding or a large Creole birthday celebration, almost all the guests, who may include family, friends, and colleagues, visibly belong to the same ethnic group. Particularly the lower classes tend to socialize in such ethnically uniform groups.

Table 3. Relations between heads of households and partners for different ethnic groups in Paramaribo in 1992 (in percentages)

\begin{tabular}{lrrrrrrr}
\hline \multicolumn{7}{c}{ Ethnic group of partner } \\
\hline $\begin{array}{l}\text { Ethnic group } \\
\text { head of hh. }\end{array}$ & Creole & Hindust. & Javanese & Mixed & Maroon & Other & Total \\
Creoles & $\mathbf{8 2}$ & 2 & 3 & 9 & 1 & 3 & 100 \\
Hindustanis & 2 & $\mathbf{9 2}$ & 2 & 3 & 0 & 1 & 100 \\
Javanese & 2 & 1 & $\mathbf{9 2}$ & 4 & 0 & 1 & 100 \\
Mixed & 23 & 9 & 13 & $\mathbf{5 0}$ & 0 & 5 & 100 \\
Maroons & 4 & 0 & 0 & 0 & $\mathbf{9 5}$ & 1 & 100 \\
\hline
\end{tabular}

Source: Schalkwijk \& De Bruijne 1999.

In Suriname, endogamy, or taking a partner from one's own ethnic group, is common, whether it is by free choice or because of pressure from the social group. Among Creoles in Paramaribo, 82 percent choose a Creole partner, and among Javanese and Hindustanis, choosing an ethnically similar partner is even more common, at 92 percent for both. Ethnically mixed persons tend mainly to marry ethnically mixed partners or Creoles. Choosing a partner of the same ethnicity is common not only among older generations, but also among the young. We observed no differences among the various age groups, though endogamy is less common among those with a higher education (on average 73 percent) than among those with a lower or no education (more than 95 percent), regardless of ethnic group. The data for 1992 and 2001 are 
almost identical, indicating that there has been little change in this type of ethnically motivated behavior.

Language is, of course, an obvious indicator of ethnic identity. In Suriname Dutch is the official language, and it is widely spoken in the workplace, at public functions, and in the media. Sranan is the lingua franca, used in a more informal setting, such as the home. Therefore, most ethnic groups in the country speak two or three languages. Members of the different ethnic groups use their "own" language more at home than outside the home. Of the largest ethnic groups, Hindustanis used their own language much more frequently than the others: 61 percent spoke Sarnami at home, whereas 43 percent of Javanese spoke Javanese with other members of the household, and only 21 percent of Creoles said they spoke Sranan at home.

The use of one's "own" language at home seems to be decreasing, and these languages are gradually being replaced by Dutch. This change can be attributed to the higher level of formal schooling that at least urban Surinamese receive. In 1992, 55 percent of households in Paramaribo indicated that Dutch was their main language. Among Creoles, far more use Dutch at home (77 percent; many lower-class families also use Dutch at home) than among Javanese (40 percent) and Hindustanis (28 percent). ${ }^{9}$ Education and ethnic background, as well as affluence and age, determine whether people use Dutch.

Ethnic groups in Suriname are also clearly demarcated along religious lines. Almost all Creoles are at least nominally Christian and distributed between Catholicism and Protestantism, though many maintain ties with their African past through Winti practices. Most Hindustanis practice Hinduism in its more liberal or orthodox forms, while a great minority professes Islam, and an even smaller group Christianity. The Javanese group has an Islamic background. ${ }^{10}$

The Catholic and Protestant churches contributed to the early emancipation of the Creole group through their educational institutions. These churches brought forth political leaders with ties to them. Through their boarding schools in Paramaribo they also provided rural Hindustani and Javanese children with opportunities. Moreover, the different Hindu and Muslim groups have formed special interest associations that participate in national activities and actively promote the interests of their members. The groups consult with each other in an interreligious council. ${ }^{11}$

9. However, particularly Creoles may overstate how much Dutch is used at home for reasons of status.

10. Although nowadays a number of Javanese are linked to Christian churches, or they delve into pre-Islamic notions known locally as "Javanism."

11. A recent example of religious tolerance is the coordination between Christians and Hindus when Good Friday and Holi Phagwa fell on the same day. 
Ethnocultural background is of importance in Surinamese politics as well. The traditional political parties have a clear ethnic basis, and even new parties formed after the "revolution of the 1980s" take care to maintain an ethnic balance in their choice of candidates. Ethnicity within politics translates into ethnically determined policy options, so that priority is assigned to certain economic sectors such as agriculture, mining, or trade because doing so favors particular ethnic groups. The ethnic color of a minister and his party has an effect on the policy choices that are made and the networks he maintains. Therefore politics has an important influence on the socioeconomic mobility of the different ethnic groups in the country.

Surinamese politics have often been called a "politics of ethnic fraternization," that is, of ethnic power-sharing, with ideology being a secondary matter. It was hoped that sharing in political power would promote the peaceful coexistence of the major ethnic groups (Breeveld 2000). Moreover, power-sharing would create and maintain political stability between the groups, guaranteeing through multiethnic coalitions that at least the main ethnic groups would partake in political power, thus preventing the group in power having access to all the scarce resources while the opposition had none. Despite the drawbacks of shared political power, such slow or difficult decision-making, and the priority given to ethnic concerns over those serving the general interest, this special brand of ethnic politics has helped avoid ethnic conflict and ethnic violence. The general elections in May of 2005 are a good example of this.

Political parties in Suriname have traditionally used the public sector as a means of gaining access to the state's resources on behalf of either their popular or ethnic base. In the past, government ministries and other public offices were distributed among coalition partners to ensure "equal access," between different political parties and thus their ethnic base, to public resources, such as civil service jobs, housing, land, loans, and permits.

The ties ethnic groups have with their countries of origin can enforce ethnic identity and ethnic boundaries. Because much migration took place more than a hundred years ago, ethnic groups in Suriname no longer maintain strong ties with India, Indonesia, or West Africa through family contact and visits. However, the embassies of these countries actively promote cultural, and sometimes economic, ties. For most Surinamese, ties with their countries of origin have been replaced with ties with the Netherlands, ${ }^{12}$ where most now have close relatives with whom they have intensive contacts.

Ethnic identity and ethnic boundaries have thus not been eliminated by the cultural and political context, but are sometimes exacerbated by them, though members of the ethnic groups apply them in a flexible rather than a rigid way.

12. And to a lesser extent the United States. 
To assess whether ethnic groups in Paramaribo access to resources differently and use these resources differently, that is, have different livelihood strategies, we took a closer look at a few indicators. The formal education one has is an asset, and it also determines how other assets are used, such as labor. Historically, Hindustanis and Javanese have had a distinctly lower level of formal education because of their rural backgrounds. Significantly, they have however largely caught up in this respect with the Creoles, though in 1992 there were relatively more Hindustani and Javanese heads of households who had attended no higher than primary school. In the last decade, there was a notable increase in the number of Hindustani and Javanese students at institutions of higher education, among them more women than men (see also De Bruijne 2001).

Table 4. Level of formal education for different ethnic groups in Paramaribo in 1992 (in percentages)

\begin{tabular}{lrccccc}
\hline Ethnic group & None & Primary & Secondary & Higher & Other & Total \\
\hline Creoles & 2 & 33 & 57 & 8 & 1 & 100 \\
Hindustanis & 8 & 41 & 46 & 4 & 1 & 100 \\
Javanese & 15 & 32 & 48 & 4 & 0 & 100 \\
Ethn. mixed & 2 & 16 & 66 & 16 & 0 & 100 \\
Maroons & 36 & 39 & 22 & 2 & 1 & 100 \\
Amerindians & 23 & 26 & 51 & 0 & 0 & 100 \\
Chinese & 2 & 6 & 69 & 8 & 8 & 100 \\
Europeans & 0 & 9 & 27 & 64 & 0 & 100 \\
Average & 7 & 33 & 51 & 7 & 1 & 100 \\
\hline
\end{tabular}

Source: Schalkwijk \& De Bruijne 1999.

Ethnic background is to some extent, though much less so than in the past, reflected in occupational choice. There are some financial activities and professions in which, though not exclusively, specific ethnic groups predominate, not only among the larger groups, but even more so for the small ethnic minority groups.

Traditionally Creoles have been oriented toward and predominant in the public sector. Historically mulattoes, who had distinct advantages because of their skin color, education, and culture, occupied higher functions within the civil service. Later they shared their positions with the upcoming group of Creoles, who, later yet, took over most of their positions. In the 1990s those with a Creole background occupied the most important public positions in the civil sector. The Creole-dominated governments in the 1960s and 1970s strongly increased the public sector and distributed jobs among their political 
base. ${ }^{13}$ As Hindustani and Javanese parties came onto the political scene and participated in multiethnic coalitions, they too provided their ethnic backing with jobs in government. These ethnicities have also increased considerably among civil servants. Though Creoles are still slightly overrepresented in the civil service when they are compared to Hindustanis and Javanese, the differences are not significant when the proportion of each group in the total urban population is taken into account. Nevertheless, Hindustanis and Javanese are more frequently employed in the private sector, or are active as small independents, than are Creoles.

To assess whether the labor market was still ethnically specialized and segmented, which was so characteristic of the colonial period, we analyzed thirty-two types of occupations together representing 95 percent of all occupations in our 1992 sample. Twenty-one of them could be qualified as jobs with a more or less even ethnic distribution, among them, significantly, all higher-ranking professions, including entrepreneurs, executives, and higher administrative and technical cadres - but also most blue-collar jobs. In five occupations, mainly the semigovernmental sector, Creoles (including people of mixed ethnicity and Maroons) were clearly overrepresented: teaching, nursing, and the military, as well as some unskilled labor such as cleaners and household personnel. Four occupations found mainly in the commercial services sector could be typified as "Asian," with a strong predominance of Hindustanis, Javanese, and sometimes Chinese: shopkeeper, trader, driver, and peddler. Two rurally oriented unskilled jobs were mainly held by Hindustanis: gardener and agricultural laborer. Javanese did not predominate in any one job, but they were relatively overrepresented in some blue-collar jobs. Ethnically mixed persons and Europeans were mainly upper-level professionals, whereas most Maroons, and to a lesser degree Amerindians, worked in blue-collar and unskilled labor.

Table 5 shows that the labor market in Paramaribo has become less ethnically specialized and segregated over time, though it is not entirely unmarked by ethnicity, and in some instances, specializations have been passed from one group to another.

Interesting differences between the major ethnic groups can be discerned in the participation in the labor process, which is in part influenced by the composition of the household. Whereas most Hindustani households are either of the nuclear (56 percent) or extended type ( 22 percent), Creole households are far more diverse, with only a minority (39 percent) living together as a nuclear family. The array of Creole households includes extended and

13. The dominance of the Creole group in public administration is most visible among women in Paramaribo. Of all employed Creole women - and their rate of labor participation is much higher than that of the other ethnic groups -70 percent worked for the government, compared to 52 percent and 40 percent for Hindustanis and Javanese, respectively. 
Table 5. Ethnic specialization in various professions in Paramaribo in different years (in percentages)

\begin{tabular}{lcccccccc}
\hline & \multicolumn{3}{c}{$1930^{\mathrm{ii}}$} & \multicolumn{3}{c}{1964} & \multicolumn{3}{c}{1992} \\
\hline Occupation & $\mathrm{Cr}{ }^{\mathrm{iii}}$ & $\mathrm{Hi}$. & $\mathrm{Cr}$. & $\mathrm{Hi}$. & Jav. & Cr. & Hi. & Jav. \\
Civil servants & 58 & 3 & $-{ }_{\text {iv }}$ & - & - & 58 & 28 & 11 \\
Teachers & 84 & 6 & - & - & - & 70 & 20 & 7 \\
Nurses & - & - & 79 & 9 &.$^{\text {v }}$ & 69 & 19 & 8 \\
Police & 86 & 3 & - & - & - & 47 & 36 & 7 \\
Merchants/shopkeepers & 12 & 7 & 15 & 34 &.. & 26 & 43 & 13 \\
Welders & - & - & 87 &.. & 7 & 61 & 10 & 29 \\
Tailors & 66 & 21 & 14 & 77 & 8 & 50 & 39 & 6 \\
Drivers & - & - & 45 & 42 & 10 & 35 & 47 & 17 \\
Peddlers & 24 & 57 & 21 & 61 & 16 & 36 & 45 & 14 \\
Gardeners & - & - & 18 & 31 & 50 & 3 & 78 & 11 \\
\hline Total & 81 & 8 & 59 & 26 & 7 & 51 & 31 & 14 \\
\hline
\end{tabular}

i. Share of total urban population

ii. Only for income tax payers; no specific data for Javanese

iii. Creoles include mixed and Maroons

iv. $-=$ no data

v. .. = less than 5 percent

Source: 1930: De Bruijne 1976; 1964: Derde algemene volkstelling ${ }^{14}$; 1992: Schalkwijk \& De Bruijne 1999.

single-parent families, childless partners, or singles. Javanese households take a more intermediate position, conforming more to the Hindustani pattern.

As for heads of households, we observed that Creoles are far more frequently economically inactive (29 percent) compared to Hindustanis and Javanese (both 15 percent). This difference in economic activity can be attributed to age: 1 in 4 Creole heads of households is sixty years or older, whereas 1 in 10 Hindustanis is. ${ }^{15}$ The number of working adults (or even children) in a household depends partly on the composition of the household. Creole households have a female head of household without a male partner far more frequently ( 1 in 4 ) than do others, so that they have fewer adults able to engage in paid labor. ${ }^{16}$ Among the households where the head had a partner,

14. Derde algemene volkstelling van Suriname 1964: Suriname in cijfers, Paramaribo: A.B.S., 1965.

15. The differences we observed in the ages of heads of households may partly be a result of the different definition the groups attribute to "head of household."

16. Although there are sometimes males living outside the household who make financial contributions to it, thereby compensating for the numerical disadvantage. 
75 percent of these partners did not engage in paid labor, almost all of them being housewives. In contrast, in similarly structured Creole households, the partners did work (52 percent). Most Hindustanis (61 percent) had only one working person in the household, or none at all, compared to 48 percent of Creoles and 46 percent of Javanese. Clearly, there are differences in how the larger ethnic groups use labor as an asset in their livelihood strategies.

It is striking that, compared to other Caribbean countries, most urban residents in Paramaribo (two-thirds) owned their own house, which contributes to a relatively high level of residential, financial, and legal security, and offers additional opportunities for income diversification. Only one-quarter of the households in Paramaribo rent our their houses commercially. More than 70 percent of Hindustani households in the city own their house. It is easier for them to do so because many of them live in the semirural district of Wanica where there family has held property (rural plots) for decades. In addition, many Hindustani households - probably more so than Creoles - have agricultural plots on the outskirts of the city. Creoles, who live mainly in the Paramaribo district, and many of them in the inner city, have had to rely more often on rental housing. Nevertheless, because urban land is not as scarce as in other cities in developing countries, a majority of Creoles (62 percent) owned their house and plot in the 1990s, a figure that had risen from 50 percent in 1980. The number of homeowners among Creoles may have risen partly as a result of the government policy of selling public housing units to the occupiers, a policy from which this group has benefited disproportionately. A majority of Javanese too (65 percent) own their own house. Among these three larger ethnic groups, there are no great differences in access to this asset. However, only a minority of Maroons and Amerindians are homeowners.

Compared to the colonial period, differences in access to and use of assets appear to have leveled off significantly between the major ethnic groups. We could not discern any clear differences in livelihood strategies regarding the key variables - education, participation in the civil service, and home ownership, with perhaps an exception in household labor, owing to differences in household composition.

\section{Affluence And Poverty among Ethnic Groups}

Compared to earlier periods, 1992 income data show that wealth and poverty in Suriname are distributed fairly evenly among Creoles, Hindustanis, and Javanese. The small European and Chinese groups are strongly overrepresented in the highest income group, whereas the group of ethnically mixed takes up an intermediate position. Maroons and Amerindians are conspicuously absent in the highest income groups. 
Table 6. Distribution of ethnic groups in Paramaribo among income categories in 1992 (in percentages)

\begin{tabular}{lccccc}
\hline Ethnic group & \multicolumn{2}{c}{ No income Lowest income } & Middle income & Highest income & Total \\
\hline Creoles & 5.6 & 29.5 & 58.2 & 6.7 & 100 \\
Hindustanis & 6.1 & 28.5 & 58.2 & 7.1 & 100 \\
Javanese & 6.0 & 31.6 & 57.6 & 4.8 & 100 \\
Ethn. mixed & 6.5 & 20.6 & 56.0 & 19.2 & 100 \\
Maroons & 7.7 & 38.7 & 52.1 & 1.5 & 100 \\
Amerindians & 15.0 & 22.5 & 62.5 & 0.0 & 100 \\
Chinese & 4.1 & 2.0 & 57.1 & 37.7 & 100 \\
Europeans & 6.5 & 3.2 & 35.5 & 54.8 & 100 \\
Other & 0.0 & 23.8 & 47.6 & 28.6 & 100 \\
\hline Total & 5.8 & 28.4 & 57.4 & 8.5 & 100 \\
\hline
\end{tabular}

Source: Schalkwijk \& De Bruijne 1999.

Because a variety of reasons (see Appendix 1) cause income not to be a very reliable indicator for measuring wealth and poverty, we constructed an index based on the possession of a number of durable consumer goods. We were able to construct this index for three different years, which enabled us to analyze the development of wealth and poverty during the last twenty years.

Table 7. Index of affluence and population groups in Paramaribo in 1980, 1992, and 2001

\begin{tabular}{lccc}
\hline Ethnic group & 1980 & 1992 & 2001 \\
\hline Creoles (general) & 4.2 & 4.2 & 5.1 \\
$\quad$ Creoles &.. & 4.1 & 4.7 \\
Mixed &.. & 5.4 & 6.4 \\
$\quad$ Maroons &.. & 2.1 & 3.6 \\
Hindustanis & 2.8 & 3.9 & 5.1 \\
Javanese & 3.5 & 4.1 & 4.8 \\
Amerindians & 3.3 & 3.1 & 3.7 \\
Chinese & 6.3 & 7.3 & 8.4 \\
Europeans & 8.0 & 8.2 & 8.8 \\
Others & 6.5 & 4.7 &.. \\
\hline Average & 3.8 & 4.2 & 5.1 \\
\hline
\end{tabular}

The index has a lowest possible value of 0 and a highest possible value of 12. See appendix 1 for a more detailed explanation of the index.

Source: 1980: Census data; 1992: Survey of 4,000 households (Schalkwijk \& De Bruijne 1999); 2001: Survey of 500 households (De Bruijne, Schalkwijk \& Verrest 2002). 
We determined that all ethnic groups, without exception, have been able to acquire more durable goods over time, reflecting a general improvement in their financial positions. Hindustanis have accumulated goods more rapidly than Creoles, whereas Javanese fall between these two groups. The financial positions of the major groups do not, however, differ considerably on this index, and, on the contrary, the index indicates that they have comparable financial positions. We could even postulate that urban Hindustanis and Javanese have caught up financially to the Creoles, though they have not overtaken them. Europeans and Chinese clearly have far more possessions, though we must once more stress that they form only very small minorities. The elite group, that is the group with a high score, is made up mainly of Creoles, ethnically mixed persons, and Hindustanis. Together these three groups make up nearly 80 percent of the most affluent households. On the other end of the scale are the Maroons and Amerindians, who have consistently low scores on all socioeconomic indicators. It is not a coincidence that these are the most recent groups to have arrived in the city.

More important seems to be the difference within the groups rather than between them, that is, the difference between rich and poor Creoles or rich and poor Hindustanis is greater than between the average Creole and the average Hindustani. In fact, the rich and poor within the Hindustani group differ more than the wealthy and poor within the Creole and Javanese group. ${ }^{17}$

In sum, the data lead to the conclusion that the socioeconomic positions of the three major ethnic groups, the Creoles, Hindustanis, and Javanese, which used to differ significantly in the colonial past, have now become more or less similar. The relatively backward position of the Hindustanis and Javanese (both of whom came to the city later than the Creoles) as far as education, access to civil service jobs, and income went, has disappeared. These two Asian groups, have not, however, overtaken the Creoles, thereby eliminating the basis for the fear of some that Creoles have been "left behind" financially. Nevertheless, there is a concern, especially among Christian churches, that a particular segment of young, lower-class male Creoles is being left behind financially and is therefore vulnerable.

We would suggest that the greater similarity between socioeconomic positions - the leveling off of these - is attributable to two interrelated factors. First, the data clearly show that the level of education has risen significantly for all three groups, though relatively more so for Hindustanis and Javanese, who, in the past, had a distinctly lower educational level compared with Creoles. Their arrival and subsequent residence in the city has caused Hindustanis and Javanese to have much better access to formal education. Their increased level of education has in turn allowed them to take advantage of better economic opportunities so that they can participate in a broader

17. This difference is based on measurements of standard deviation for each group. 
range of economic activities. Second, access to government jobs has been very important. All major ethnic groups, including the Maroons, have gained access to the prized civil service, and their presence in this sector more or less mirrors their relative numerical share in the urban population, though Creoles are still slightly overrepresented in the civil service. Improved access to civil service jobs for all of the ethnic groups, resulting in part from rising educational levels, appears mainly to be a consequence of the way political parties have consistently used their administrative apparatus as a means to further the emancipation of their ethnic basis.

\section{The Spatial Dimension of Ethnic Identity and Boundaries}

We assumed, basing ourselves on theory, that nowadays ethnic spatial segregation would have diminished. A cursory understanding of fundamental changes in the spatial layout of Paramaribo after World War II is necessary to understand the present-day residential patterns.

The pace of urbanization picked up after 1950, leading to a doubling of Paramaribo's population in the 1950s and 1960s. At the same time, the national economy started growing more quickly. Economic growth and development, which were then still centrally planned, caused the government apparatus to expand and the private sector to grow. Both sectors needed physical space to accommodate their increased administrative and economic activities, particularly their offices. Consequently, there was significantly more demand for space in the city center from both the government and the private sector. Many homes disappeared from the center. Front homes were turned into offices and shops, whereas backyard houses were torn down and frequently replaced by storage space. At the same time, there was a higher demand for residential space, especially for better and comfortable space, from upper and middle classes, which were growing because people were able to take advantage of increased economic activities, the expansion of the planning apparatus, and higher education. In fact, a new elite and middle class were developing, and they were taking over the role of the old colonial elite of Dutch, Jews, and mulattoes who had largely left the colony. The new group of affluent urbanites had new views on residential comfort that were influenced by developments in the United States and Europe, where detached bungalows with gardens in quiet residential suburban areas, far away from the crowded city center, became the norm for the well-to-do. Gradually the new spatial norms trickled down to the less affluent, so that the Paramaribo standard of $300 \mathrm{~m}^{2}$ for a public housing plot may seem spacious compared to other cities in the Caribbean.

The prevalence of space devoted to economic activities over that for residential purposes, the growth of the urban population and elite, and the chang- 
ing norms for residential comfort all led to a change in the spatial development of Paramaribo, for the elite moved from the center to new residential suburbs after 1950. New developments in transport and technology facilitated the suburbanization of the elite; the introduction and more common use of personal cars, public transport, and telephones.

It was the government that initiated the development of new suburban residential zones with residential lots, roads, public transport, and new schools. The private sector soon took over the government's initiative and began suburbanizing privately and on a large scale, offering residential lots and a basic residential infrastructure.

The new spatial organization of Paramaribo had an important influence on residential patterns. People were differentiated in the new suburban zones exclusively on the basis of financial status, income, and purchasing power. Economically homogeneous residential areas (elite/middle class/lower class) came into being. Ethnicity, that is, the effects of segregated economic activities or of a preference for ethnic proximity, did not make themselves felt in these new neighborhoods. Ethnic residential mixing was furthered by the gradual ascendance of Hindustanis and, to a lesser extent, Javanese, to the new economic middle class and elite.

The new residential areas, which were subdivisions of former agricultural land and wasteland around the city, have been the most important reasons for urban land development for Paramaribo since 1950, though even more so in the 1960s. In this period, private developers added 800 hectares, or some 12,000 new building lots, to the city's housing market. In general, agricultural land north of Paramaribo was owned by agricultural companies in possession of the former plantations, and they divided these up into relatively large residential lots that were attractive for the elite and middle class. Agricultural land used for animal husbandry to the west of Paramaribo was chiefly owned by "Boeroes," Dutch colonists who converted these tracts into prime residential areas or sold them to developers. To the south, agricultural lands were owned mainly by Hindustanis. The poorly drained holdings were not suitable for quality large-scale lots, and they were subdivided into cheaper lots for the less affluent population. The physical extension of Paramaribo has therefore especially been the work of the private sector.

Since the national government of Suriname does not have any decentralized form of administration for policy implementation, judicial competencies, or financial resources, its role in the physical development of the capital has always been quite limited. The legal framework for urban planning is very weak; the city has no legal administrative authority responsible for its planning and development, nor does it have a legalized urban development plan. Thus, authorities are left with few tools for planning and guiding the physical expansion or restructuring of the city. 

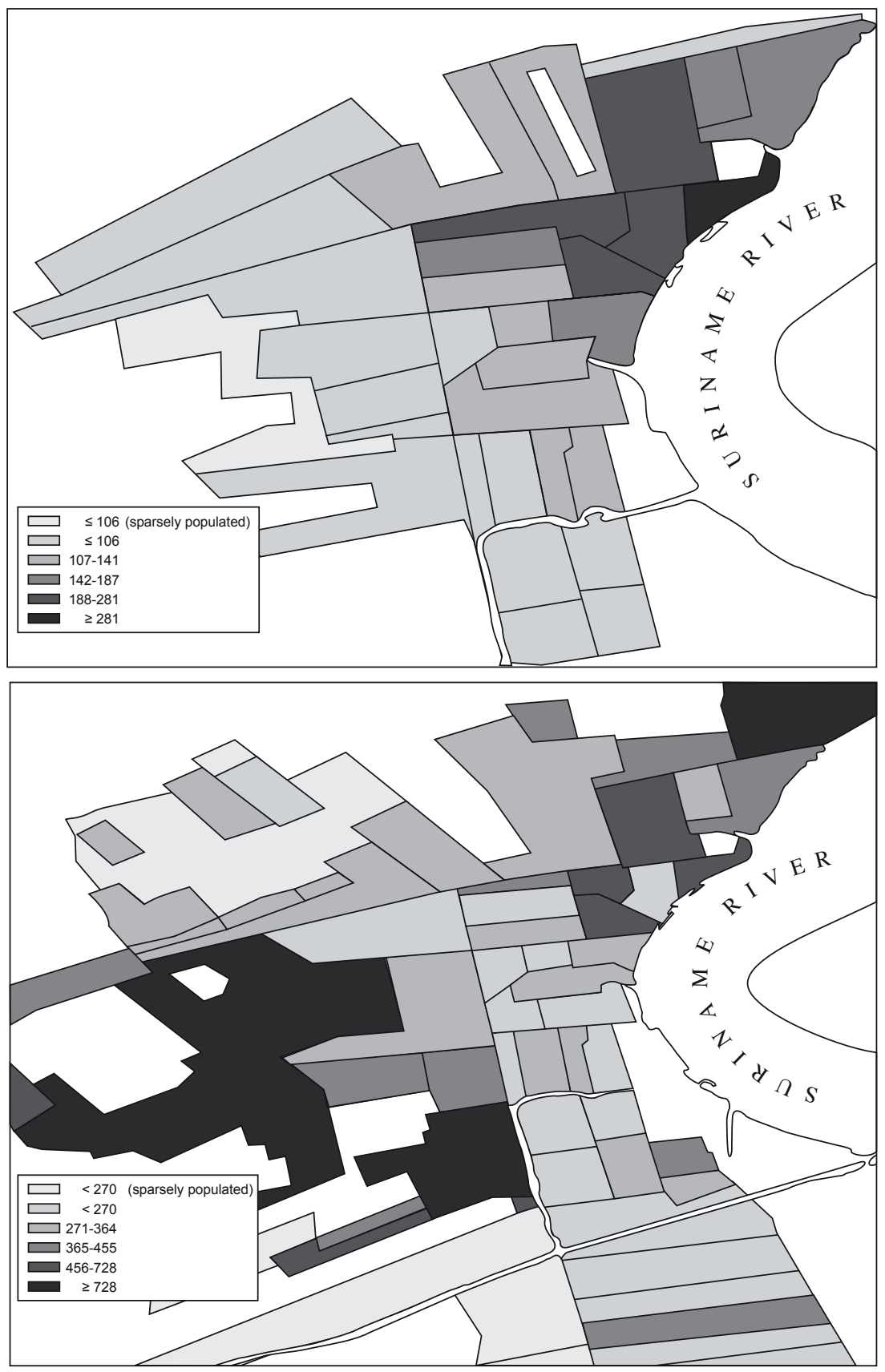

Map 4. Average tax value in Surinamese guilders of houses in Paramaribo in 1950 and 1966. Source: Property value registers in Paramaribo 1964 and 1966 (De Bruijne 1976) 
After the 1950s, however, with the growth of the urban population and the increase in housing opportunities for the elite and middle class, the government felt it was necessary to provide housing for lower-income groups who were not able to afford privately owned subdivisions. The government thus embarked upon a program of low-income housing, and from 1950 to 1974 , completed fifteen housing projects resulting in a total of 3,000 housing units. The high building standards (detached concrete houses built on lots of $300 \mathrm{~m}^{2}$ ) meant high construction costs, for which huge sums of external funding was needed - and given - almost exclusively from Dutch development aid. The low rents charged to the tenants, coupled with the lack of discipline in collecting these rents, as well as the intervention of politicians who asked for financial arrangements for their clients if they ran up debts, made cost recovery and revolving financing impossible. Their high quality and low rents made the houses very attractive to lower-class and middle-class income groups. In practice, most houses were awarded to civil servants who had the best political connections.

\section{Current Ethnic Residential Patterns}

The inner city of Paramaribo is populated mainly by Creoles. They have dominated this area, residentially, for centuries, and together with the mixed groups and the Maroons, they make up three-quarters of the inner-city population. Hindustanis, Javanese, and other groups form small minorities in the center of Paramaribo, but the inner city's residential function is gradually losing ground to its economic function.

The district of Wanica constitutes the semirural periphery of the capital. Since the beginning of the twentieth century, it has traditionally been the residential area of Hindustanis, who make up 56 percent of its population. Javanese are relatively strongly represented here as well, and they form almost one-quarter of the population at the edge of the city, though they are concentrated mostly in a few areas that were formerly villages. In the city's semirural periphery Creoles form a small minority of some 15 percent, whereas other ethnic groups are almost absent.

The older center and the semirural periphery are linked by a broad and more diffuse concentric intermediate zone that houses most of the urban population. It is continually increasing in size as a result of ongoing commercial subdivisions. This is the area of private housing development lots and a few government housing estates that have been developed since the 1950 s as part of a process of rapid urban transformation. No one specific ethnic group dominates this zone, but Creoles are relatively overrepresented in the western and southern sections, Hindustanis in the northwest, Javanese in the north, and Maroons in the south. 
There are marked differences between the ethnic groups with regard to the type of neighborhood, based on how the neighborhood originated. Quite clearly, public housing schemes are overwhelmingly inhabited by Creoles, and the Hindustanis still form a large majority in the semirural urban fringe. Javanese are distributed most equitably. The group of ethnically mixed persons is quite strongly represented in the more elite private subdivisions, which corresponds with their high economic status. Maroons, on the other hand, are found in the lower-class private developments. More than half of all Maroons reside in such areas.

Table 8. Distribution of ethnic groups by type of neighborhood in 1992 (in percentages)

\begin{tabular}{lccccc}
\hline Type of neighborhood & Creoles & Hindustanis & Javanese & Ethn. mixed & Maroons \\
\hline Old inner city area & 51 & 15 & 10 & 13 & 7 \\
$\begin{array}{l}\text { Public housing scheme } \\
\text { Lower middle-class private }\end{array}$ & 71 & 8 & 4 & 9 & 4 \\
$\quad$ development & 30 & 35 & 17 & 8 & 10 \\
$\begin{array}{l}\text { Upper- and middle-class } \\
\text { private development }\end{array}$ & 35 & 24 & 10 & 20 & 1 \\
Peri-urban area & 13 & 65 & 16 & 2 & 2 \\
\hline Total share in population & 39 & 29 & 12 & 11 & 5 \\
\hline
\end{tabular}

Source: Schalkwijk \& De Bruijne 1999:111.

We have distinguished four types of neighborhoods in Paramaribo on the basis of ethnic characteristics: Creole, Hindustani, Javanese, and ethnically mixed. One of the ethnically mixed neighborhoods is dominated by the Maroons.

We have typified a neighborhood as "Creole" or "Hindustani" if that particular group is overrepresented, that is, if the share of this ethnic group is much greater than one would expect on the basis of their presence in the city as a whole. We have measured overrepresentation according to two criteria: the relative share of the ethnic group is at least one-and-a-half times the average share of this group in the city as a whole, and more than 50 percent of the population of the neighborhood belongs to the ethnic group. Because Creoles make up 39 percent of the population of the city, and Javanese only 13 percent, statistically, Creole neighborhoods will be prevalent.

Ethnically mixed neighborhoods dominate: in almost half the neighborhoods (37 out of 79) no one ethnic group dominates, especially in the north and northwestern parts of Paramaribo. One-quarter of the neighborhoods can be qualified as "Creole," and these can be found in the old inner city and west and south of the city. Almost all housing estates built by the government have a predominantly Creole population. 
Neighborhoods populated mainly by Hindustanis - one-fifth of all neighborhoods - may be found along the Kwatta highway leading out of the northwestern part of the city (see Map 1) and in the semirural periphery in the Wanica district. These neighborhoods are large but have very low population densities. The highest concentration of Hindustanis measured in one neighborhood was 88 percent. There are three neighborhoods where Javanese predominate in the north of the city, and one in the south, a former village, now a suburb of Paramaribo. Creole neighborhoods have a more homogeneous composition than the Hindustani and Javanese neighborhoods.

The ethnically heterogeneous neighborhoods are found in the north of the city and in a concentric layer around the inner city. It is interesting that these neighborhoods consist not only of households of different ethnic groups, but also a relatively large number of ethnically mixed persons.

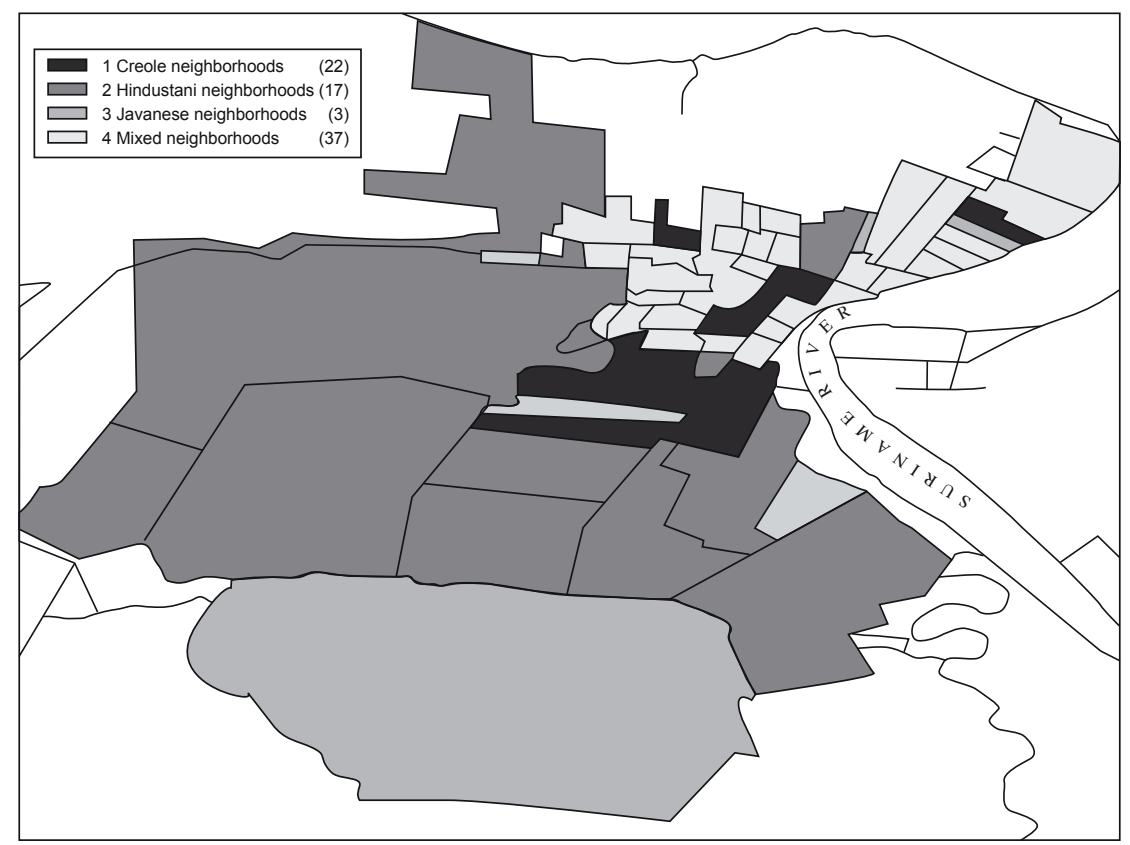

Map 5. Ethnically homogeneous and heterogeneous neighborhoods in Paramaribo, 1992

To determine statistically what factors help explain the residential pattern in Paramaribo, we carried out a factor analysis, using thirty-eight variables of households grouped into four "dimensions" or broader categories: socioeconomic status, demographic characteristics, ethnicity, and housing quality. With the help of this statistical method, we were able to determine what cor- 
related underlying factors contributed to the differences between the seventynine neighborhoods in Paramaribo.

We also determined which factors had the most weight in explaining the residential patterns we observed. From ordering these factors we determined that affluence and poverty are the most important ones for classifying and typifying neighborhoods, and thus residential patterns, in Paramaribo. Our analysis revealed that 30 percent of the variance ${ }^{18}$ is a result of a factor that can best be labeled as "poor, large households" with a high positive score on variables such as "low education," "low income," and "popular class." This factor thus has a clear socioeconomic signature. ${ }^{19}$

The second factor, which explains 18 percent of the variance, is clearly related to demographics, showing a strong positive correlation with variables such as "older," "non-working," and "female" heads of households. The ethnocultural dimension is but the third in line with a variance of 11 percent. It has high positive scores on the variables "Creole," "Maroon," and "Srananspeaking," and a high negative score on "Hindustani." These results are largely consistent with earlier findings for the period of the 1960s (De Bruijne 1976).

\section{CONCLUSION}

In a city as ethnically diverse as Paramaribo, ethnic identities and ethnic boundaries inevitably help its residents define their place in urban society. The data show that belonging to an ethnic group is considered important in Paramaribo. Particularly in the private spheres of culture, social gatherings, religion, and the choice of a partner, people express a strong preference for their own ethnic group, not only older generations, but the younger ones as well, indicating that certain aspects of ethnic identity will remain important in the near future.

However, the data also show patterns of increasing communality between ethnic groups over time, whereby we can infer a gradual but limited process of assimilation and integration. Several indicators point in this direction: the use of a common language, Dutch, is increasing, not only in school and at the workplace, but also in the home. More members of all ethnic groups are participating in formal education, and the three major ethnic groups now have more or less equal access to education. In the labor market, the sharp ethnic division or segmentation so characteristic of the colonial period appears to be disappearing gradually. Importantly, all ethnic groups are now relatively well represented in the civil service. With increasing educational levels, both

18. See the appendix for an explanation of this concept and our methods.

19. It must be added that in Paramaribo differences in wealth are not as rigid as in other Caribbean cities. Often personal linkages, which may be based on family ties, between households in rich and poor neighborhoods do exist and function. 
ethnic networks and labor specialization seem to become less important. We can therefore postulate that lasting exposure to shared national facts and institutions, such as history, education, language, the judicial system, and even politics, appears, as we expected, to strengthen processes of unification and acculturation. The three major ethnic groups, at least, have a more or less similar socioeconomic position, and certainly more so than in the colonial past.

Spatially, we discerned similar processes of increasing geographical convergence and proximity between ethnic groups. Colonial history, and specifically the sequential migration to the city, produced a basic residential pattern of general and relative locational differentiation, with Creoles in the city center, and Hindustanis and Javanese in the urban periphery, without there being, however, strong ethnic segregation. Since the 1960s, with the private sector providing the bulk of the land and development for the housing market, economic position and income have become the distinctive sorting mechanisms, causing - indirectly - obvious ethnic blending, with the residential composition of private subdivisions reflecting the relative presence of the ethnic groups in the city. Residential ethnic mixing can in fact be expected to increase in the future, and the mixed intermediate zone of Paramaribo will likely broaden both toward the periphery and the center as commercial forces gain more momentum and government intervention is further limited. Government intervention produced "anomalous" ethnically segregated neighborhoods in the past, but market forces contribute to ethnic blending.

It is relevant to note that Suriname has not witnessed any periods or even incidents of ethnic conflicts - with the exception of the "war of the interior" of the 1980s. Nor has it experienced ethnic tension during its recent history as other plural societies, such as nearby Guyana and Trinidad, have. In a world where ethnic and religious identity and cultural awareness are becoming more explicit, the different ethnic groups of Suriname - at least those in its capital - seem to have found a modus vivendi, living together in relative harmony in a confined geographical setting. Long-lasting exposure to each other and to each other's culture, with Creoles, Hindustanis, and Javanese living together as neighbors and maintaining daily interaction, seems to have contributed to this harmony.

\section{Appendix: Data And Method}

\section{Data}

The data in the historical section of this article and elaborated in De Bruijne's publication of 1976 are based on original and official published sources. For 1850 , we used original neighborhood registers, as well as property value registers, consulted in 1965 in the National Archives of Suriname. For 1921 
we used the First General Population Census, now kept in the Dutch National Archives in The Hague. We also used the Register of Income Tax of 1930 and the property value register of 1925, both available in 1965 at the National Archives in Paramaribo. For 1950 and 1964 we used the published results of the Second and Third General Population Censuses. They were combined with a sample of 3,000 households on which data were collected in 1966 and a study of the original property value registers of 1946 and 1966.

We were allowed to use original census material for 1980. The original records have now probably been lost.

Because there was no census conducted in the 1990s, we decided to hold a large household survey using a basic questionnaire. Including households from all geographic areas of Greater Paramaribo and the urbanized parts of the district of Wanica, was given great importance, as this would give us a valid sample of the total urban population. Because no official administrative areas exist other than numbered district areas used for censuses, we divided Greater Paramaribo into smaller residential areas, or neighborhoods differentiated by internal historical-morphological unity, that is, private subdivisions or housing estates, and boundaries with adjoining areas. In total we identified seventynine neighborhoods, which included all the streets of Paramaribo.

Next we selected a sample of fifty households from each of these neighborhoods, with a simple correction for the size of the sample in larger residential areas and with the stipulation that houses from every street of the area had to be included in the sample. This gave us a total of just over 4,000 households. An adjustment in the size of the sample was made for larger neighborhoods.

A census had been held in 2003. Unfortunately the original material was destroyed by fire, and only a few basis data could be published. In 2004 there was a new census conducted, but while we were composing this study, only a few data could be used. To validate the data from the 1992 survey and check for the continuation of trends identified in our 1999 publication, we carried out a limited survey in ten neighborhoods in 2001, again using a sample of fifty households from each neighborhood. The neighborhoods were selected on the basis of their origin so that two of each type of neighborhood identified in 1992 (i.e. housing estates, private subdivisions, older inner city areas, etc.) were included.

\section{Calculation of Index of Affluence and Poverty}

To be able to differentiate realistically between rich and poor in Paramaribo, we could not use income as an exact indicator for economic position, owing to the multiple and often hidden sources of income that many households have (including remittances, secondary jobs, and illegal activities such as smug- 
gling and dealing drugs ${ }^{20}$ ) that do not surface in censuses and surveys. In most of the 1980s and 1990s extreme inflation hit the country, rendering data on income useless. Instead, we constructed our own index of affluence and poverty, which is based on the possession of a number of durable consumer goods, and which in Suriname are considered as "naturally belonging" to a certain economic class. In the surveys of 1992 and 2001, respondents were asked if they possessed the following consumer goods: a television, refrigerator, washing machine, car (and the age of the car), and air conditioner. ${ }^{21}$ These variables were weighed against each other on the basis of their relative exclusivity: a TV, 1 point; a fridge, 1 point; a washing machine, 2 points; a car, 1-4 points (depending on its age); and an air conditioner 4 points. Table 9 shows how households scored in terms of consumer goods possession.

Table 9. Possession of durable consumer goods in 1992 (in percentages)

\begin{tabular}{lcc}
\hline Durable consumer goods & Present & Absent \\
\hline Refrigerator & 86 & 14 \\
TV & 85 & 15 \\
Washing machine & 64 & 36 \\
Car & 41 & 59 \\
Air conditioner & 6 & 94 \\
\hline
\end{tabular}

Households could receive a minimum score of 0 points if they did not possess any of the relevant goods, and a maximum of 12 points if they owned all the above. Those scoring 8-12 points were considered to be the "elite," 5-7 the "middle class," 2-4 the "popular class," and 0-1 the "underclass."

\section{Index of Dissimilarity, Relative Centrality, and Concentration}

The index of dissimilarity is a measure of segregation between two or more groups, such as ethnic groups, calculated according to the following formula:

$\mathrm{D}=0.5 \times \sum\left[\frac{\mathrm{bi}}{\mathrm{B}}-\frac{\mathrm{wi}}{\mathrm{W}}\right]$

in which bi and wi are population counts in areal unit 1, and B and $\mathrm{W}$ are the total population counts of the two groups in the whole study area.

The index of relative centrality is a measure of the relative distance of a group from the city center. The lower the score, the shorter the distance from the center.

20. Suriname has a flourishing drug trade.

21. Computers and mobile phones could be used as indicators nowadays, but in 1992, these goods were not yet commonly available in Suriname. 
The concentration index measures how concentrated a group is in a certain area relative to its share in the total population of the larger area (in our case, Paramaribo).

\section{Factor Analysis}

Factor analysis allows us to order and reduce a large amount of data to core data. The objective is to indicate the cohesion between a large number of variables that characterize a subject (residential neighborhoods) and reduce these variables to a number of core variables or factors. By doing a factor analysis with the help of the statistical program SPSS, one tries to identify the underlying factors that can, in essence, be considered a combination of the original variables.

With the 1992 survey we collected basic data on 4,000 households in seventy-nine neighborhoods. The data on the households were sorted according to neighborhood, giving us a picture of the population composition of the neighborhoods. Thirty-seven basic characteristics were chosen and grouped around four dimensions or broader categories of variables: residential, demographic, ethnocultural, and socioeconomic. We produced a correlation matrix that indicated whether there were relationships between the variables. Theoretically one would expect a high frequency of mutual relationships between variables within one dimension, and we did actually find this. For example, the variables "higher education" and "higher income" within the socioeconomic dimension showed a positive correlation (r) of 0.87 . Then we did a factor analysis by choosing the Principal Component Analysis method, which indicates independent factors or components.

The number of new factors that emerged was limited to the five main ones explaining 70 percent of the variance. Variance is the part of the original variables represented by the new factors. After studying the matrix of loadings we chose the so-called Varimax rotation, which enabled us to assign a high score one just one factor and low scores on other factors to clusters of variables.

The analysis of the matrix of loadings indicated that factors were found that clearly differ from each other. The first factor showed high loadings on the variables of the socioeconomic dimension, whereas the second factor in importance had a demographic dimension. The third factor incorporated ethnic-cultural variables, whereas the fourth factor show a relationship with residential quality. The fifth factor showed no clear pattern. 


\section{REFERENCES}

Breeveld, Hans, 2000. Jopie Pengel 1916-1970: Leven en werk van een Surinaamse politicus. Schoorl, the Netherlands: Conserve.

De Bruijne, AD, 1976. Paramaribo, stadsgeografische studies van een ontwikkelingsland. Bussum, the Netherlands: Romen.

-, 2001. A City and a Nation: Demographic Trends and Socio-Economic Development in Urbanising Suriname. In Rosemarijn Hoefte \& Peter Meel (eds.), Twentieth-Century Suriname: Continuities and Discontinuities in a New World Society. Kingston: Ian Randle; Leiden, the Netherlands: KITLV Press, pp. 23-47.

-, Aart SchalkwiJk \& Hebe Verrest, 2002. Een korte verkenning van Paramaribo. Amsterdam: AGIDS, Universiteit van Amsterdam.

Hoefte, Rosemarijn \& Peter Meel (eds.), 2001. Twentieth-Century Suriname: Continuities and Discontinuities in a New World Society. Kingston: Ian Randle; Leiden, the Netherlands: KITLV Press.

Hoogbergen, Wim \& OKKo ten Hove, 2001. De vrije gekleurde en zwarte bevolking van Paramaribo, 1762-1863. Oso, tijdschrift voor Surinaamse taalkunde, letterkunde, cultuur en geschiedenis 20:306-20.

Moser, Caroline, 1998. The Asset Vulnerability Framework: Reassessing Urban Poverty Reduction Strategies. World Development 26:1-19.

Musterd, Sako, Wim Ostendorf \& MatthiJs Breebaart, 1998. Multi-Ethnic Metropolis: Patterns and Policies. Dordrecht, the Netherlands: Kluwer Academic Publishers.

Premdas, Ralph R. (ed), 2000. Identity, Ethnicity and Culture in the Caribbean. St. Augustine, Trinidad: The University of the West Indies.

SAnders, Jimy M., 2002. Ethnic Boundaries and Identity in Plural Societies. Annual Review of Sociology 28:327-57.

SCHALKWIJK, AART \& Ad de Bruijne, 1999. Van Mon Plaisir tot Ephraïmszegen: Welstand, etniciteit en woonpatronen in Paramaribo. Paramaribo: Leo Victor.

Verberk, Geneviève, Peer Scheepers \& Maurits Hassankhan, 1997. Etnocentrisme in Suriname. Oso, tijdschrift voor Surinaamse taalkunde, letterkunde, cultuur en geschiedenis 16:133-45.

VERREST, HeBE (forthcoming). Working from Home: Urban Livelihoods in Low-Income Surinamese and Trinidadian Households. In Rivke Jaffe (ed.), The Caribbean City. Kingston: Ian Randle.

AD DE BRUIJNE \& AART SCHALKWIJK

Department of Geography and Planning

University of Amsterdam

1018 VZ Amsterdam, the Netherlands

<a.bruijne@frw.uva.nl>

<aschalkwijk@yahoo.com> 